Submitted to the Journal of Business Ethics

Chad Albrecht, Ph.D.

Daniel Holland, Ph.D.

Ricardo Malagueño, Ph.D.

Simon L. Dolan, Ph.D.

Shay S. Tzafrir, Ph.D.

\title{
The Role of Power in Financial Statement Fraud Schemes
}

\begin{abstract}
:
In this paper, we investigate a large-scale financial statement fraud to better understand the process by which individuals are recruited to participate in financial statement fraud schemes. The case reveals that perpetrators often use power to recruit others to participate in fraudulent acts. To illustrate how power is used, we propose a model, based upon the classical French and Raven taxonomy of power, that explains how one individual influences another individual to participate in financial statement fraud. We also provide propositions for future research.
\end{abstract}

Keywords: .... 


\section{Introduction}

In recent years, fraud and other forms of unethical behavior in organizations have received significant attention in the business ethics literature (Uddin and Gillet, 2002; Elias, 2002; Rockness and Rockness, 2005; Robison and Santore, 2011), investment circles (Pujas, 2003; Albrecht, et al., 2011), and regulator communities (Farber, 2005; Ferrell and Ferrell, 2011). Scandals at Enron, WorldCom, Xerox, Quest, Tyco, HealthSouth, and other companies created a loss of confidence in the integrity of the American business (Carson, 2003) and even caused the accounting profession in the United States to reevaluate and reestablish basic accounting procedures (Apostolon and Crumbley, 2005). In response to the Enron scandal, the American Institute of Certified Public Accountants issued the following statement:

"Our profession enjoys a sacred public trust and for more than one hundred years has served the public interest. Yet, in a short period of time, the stain from Enron's collapse has eroded our most important asset: Public Confidence.” (Castellano and Melancon, 2002, p. 1)

Financial scandals are not limited to the United States alone. Organizations in Europe, Asia and other parts of the world have been involved in similar situations. Notable cases include Parmalat (Italy), Harris Scarfe and HIH (Australia), SK Global (Korea), YGX (China), Livedoor Co. (Japan), Royal Ahold (Netherlands), Vivendi (France), and Satyam (India). The business community worldwide has experienced a syndrome of ethical breakdowns, including extremely costly financial statement frauds.

An organization's financial statements are the end product of the accounting cycle and provide a representation of a company's financial position and periodic performance. The accounting cycle includes the procedures for analyzing, recording, classifying, summarizing, and reporting the transactions of a business or organization. Financial statements are a legitimate part of good management and provide important information for stakeholders (Power, 2003; Epstein et al., 2010). Financial statement fraud has been defined as an intentional misrepresentation of an organization's financial statements (National Commission on Fraudulent Financial Reporting, 1987).

Financial statement fraud is primarily a top-down form of fraud that negatively impacts individuals, organizations, and society. As a result, it is important to understand why individuals become engaged in financial statement fraud. While research has suggested how a single individual becomes engaged in financial statement fraud (Ramos, 2003; Wolfe and Hermanson, 2004; LaSalle, 2007, Nocera, 2008), we still do not understand how groups of individuals become involved. In this paper, we seek to contribute to the literature by considering how top management recruits others to participate financial statement fraud.

\section{Literature Review}

Various efforts have been made to curb fraud and other forms of organizational corruption. For example, legislation such as the Sarbanes-Oxley Act that was passed in 2002 by the United States Congress was created to minimize financial statement fraud. One of the top priorities of the Public Company Accounting Oversight Board (PCAOB) has been to minimize the occurrence of fraud (Hogan et al., 2008). Other organizations, such as the Association of Certified Fraud Examiners (ACFE) were created to educate and train professionals to detect and prevent fraud.

Research that addresses the behavioral aspects of fraud has generally focused on various theories of management, especially that of agency theory (Albrecht et al., 2004). Agency theory assumes a principle-agent relationship between shareholders and management (Jensen 
and Meckling, 1976). Under agency theory, top managers act as 'agents', whose personal interest do not naturally align with company and shareholder interest. Agency theory assumes that management is typically motivated by self-interest and self-preservation. As such, executives will commit fraud because it is in their best, personal, short-term interest (Davis, et al., 1997). In order to limit financial statement fraud and other forms of organizational corruption, researchers suggest that organizations provide employee incentives that better align management behavior with shareholder goals. Furthermore, shareholders seek to institute controls that will limit the possibility that executives will maximize their own utility at the expense of shareholders (Donaldson and Davis, 1991).

In the last few years, there has been an increased volume of research by scholars within the management community that address fraud and other forms of corruption from a humanistic approach. Recent research in this area has addressed circumstances that influence selfidentity in relation to organizational ethics (Weaver, 2006), collective corruption in the corporate world (Brief et al., 2000), normalization and socialization, including the acceptance and perpetuation of corruption in organizations (Anand et al., 2004), the impact of rules on ethical behaviour (Tenbrunsel and Messick, 2004), the mechanisms for disengaging moral control to safeguard social systems that uphold good behavior (Bandura, 1999), and moral stages (Kohlberg, 1984). In addition to this work, there has been substantial research into the various aspects of whistle blowing. (Dozier and Miceli, 1985; Near and Miceli, 1986).

\section{Classical Fraud Theory and the Initiation of Financial Statement Fraud}

Classical fraud theory has long explained the reasons that a single individual becomes involved in financial statement (or any type of) fraud. This theory suggests that there are three primary perceptions or cognitions that influence individuals' choices to engage in fraud. These three factors are often represented as a triangle and consist of perceived pressure, perceived opportunity, and rationalization (Southerland, 1949; Cressey, 1953; Albrecht et al., 1981).

The first element in the fraud triangle is that of pressure or motivation. Motivation refers to the forces within or external to a person that affect his or her direction, intensity, and persistence of behavior (Pinder, 1998). At a very basic level, motivation starts with the desire to fulfill fundamental needs, such as food, shelter, recognition, financial means, etc. These desires lead to behaviors that the individual believes will result in the fulfillment of such needs. In financial statement fraud, the motivation or pressure experienced by the initial perpetrator is often related to the potential negative outcomes of reporting the firm's true financial performance.

Financial statements are used by shareholders to measure the performance of the firm versus expectations. The results have a significant influence on the company's stock price.

Executives' job security and financial compensation are often dependent on maintaining strong financial performance and rising stock prices. Thus, top managers feel tremendous pressure to meet or exceed investors' expectations and may even consider using fraudulent means to do so.

The second element of the fraud triangle is that of opportunity. Perpetrators need to perceive that there is a realistic opportunity to commit the fraud without facing grave consequences. Opportunity is largely about perceiving that there is a method for perpetrating the fraud that is undetectable. A person that perceives a reasonable opportunity for fraud typically senses that he or she will not get caught, or it would be unlikely that any wrongdoing could be proven. If an individual perceives such an opportunity, he or she is much more likely to consider the possibility of initiating unethical actions. Of course, shareholders or boards of directors strive to reduce the perception of opportunity by implementing systems and controls 
(e.g. auditing procedures) that make it more difficult to perpetuate a fraud. However, some people, particularly executives with considerable authority, may suppose that they can manipulate and control their environment in a way that will reduce the likelihood of detection.

Rationalization is the third element of the triangle. Most people are basically honest and have intentions to be ethical. Thus, even the consideration of committing fraudulent acts results in significant cognitive dissonance and negative affect (Aronson, 1992; Festinger, 1957). In order to overcome such dissonance, fraud perpetrators generally try to find a way to reconcile their unethical cognitions with their core values. As a result, they seek out excuses for their thoughts, intentions, and behaviors through logical justification so that they may convince themselves that they are not violating their moral standards (Tsang, 2002). Typical excuses for financial statement fraud may include, "This is our only option", "Everybody is doing it", "It will only be short-term", or "It is in the best interest of the company, shareholders, or employees". Such rationalizations aim to reduce the perception of unethicality or to shift the balance of the equation to a more utilitarian "it may not be ideal but it is for the greater good."

Classical fraud theory suggests that fraud is most likely to take place when all three elements are perceived by the potential perpetrator. However, the three factors work together interactively so that if more of one factor is present, less of the other factors need to exist for fraud to occur (Albrecht et al., 1981). It is also important to note that the theory is based on perceptions. In other words, the pressures and opportunities need not be real, only perceived to be real.

\section{Collusion between Perpetrators}

Recent research into financial statement fraud has suggested that nearly all financial statement frauds are perpetrated by multiple players within the organization working together (The Committee of Sponsoring Organizations of the Treadway Commission, 2002; Association of Certified Fraud Examiners, 2012; Zyglidopoulos and Flemming, 2008, 2009; Burke, 2010). As such, it is necessary to understand the relationship that takes place between the initial perpetrator of a fraudulent act and any additional conspirators.

Research on the perpetuation of fraud in organizations has focused on diffusion (Strang and Soule, 1998; Baker and Faulkner, 2003), social networking (Brass, Butterfield, and Skaggs, 1998) and the normalization of deviant practices (Earle, Spicer and Peter, 2010). While each of these studies has enhanced our understanding of fraud in organizations, there remains a significant gap in our knowledge regarding how individuals are influenced to join a fraudulent scheme. In others words, we still do not know the processes by which one individual - after he or she has become involved in a financial statement fraud-recruits other individuals to participate. While the fraud triangle explains why a single individual becomes involved in financial statement fraud, the theory does not inform us as to how large groups of individuals become involved. The fraud triangle is limited in that it only provides a psychological glimpse of a single person's perceptions and why he or she may choose to participate in fraudulent behavior through pressure, opportunity, and rationalization. We build on this theory by considering how the leading perpetrator may influence the perceptions of pressure, opportunity, and rationalization in a subordinate during the recruitment process. We start by presenting an illustrative strategic case of a large public financial statement fraud. Next, we propose a power-based, dyad reciprocal model to explain the process of how collusive acts, particularly those of financial statement fraud, occur in organizations. In so doing, we offer propositions regarding how individuals within an organization are oftentimes 
successfully recruited to participate in financial statement scandals. We conclude with a discussion and recommendations for future research.

\section{Strategic Case: A Fortune 500, Billion-Dollar Fraud}

In order to better understand how individuals are recruited to participate in financial statement fraud, we investigated a large financial statement fraud that recently occurred at a U.S. "Fortune 500" company. At the time of the fraud, the company was publicly traded on the New York Stock Exchange and was considered to be one of the leading growth companies in the United States. Because the fraud is still under trailing litigation, we are not authorized to disclose the name of the company. However, it should be noted that the case is one of the well-publicized, financially significant, financial statement frauds that occurred in the United States over the last few years. By signing confidentiality agreements, we were able to interview expert witnesses and gain access to various court documents including depositions, complaints, pre-trial motions, amended complaints and exhibits. We spent hundreds of hours studying these documents.

In our investigation, we discovered that the financial statement fraud started when significant financial pressure was put on management, including the CFO and others. Management was concerned that not meeting publicly available earnings forecasts would result in significant declines in the market value of the stock. By analyzing the financial statements, it is possible to see the exact amount that was manipulated each quarter in order to meet earnings forecasts. In fact, in every quarter, management guided the analysts to increasing earnings per share. Management would then manipulate the financial statements in exactly the amount needed to meet the consensus of the analyst's forecasted expectations. For example, if real earnings per share were \$.09 and Wall Street's consensus expectation was \$.19 per share, management would manipulate the statements to add $\$ .10$ per share for a total of $\$ .19$ per share. The chief executive officer (CEO), the chief financial officer (CFO) and the chief operating officer (COO) all felt substantial pressure to meet the analyst's forecasted expectations for the organization. At first, management used acceptable but aggressive accounting methods to reach the desired numbers. When aggressive accounting methods no longer achieved the desired targets, the top management team pressured the CFO to do "whatever was necessary" to meet the published numbers.

The CFO was left to himself to decide how to meet the objective. At first, the CFO reached into future reporting periods to pull back a few expected revenue transactions into the current period. When that was no longer plausible, the CFO used 'topside journal entries' (accounting entries made to the trial balance with no support), false revenue recognition, and understatement of liabilities and expenses to perpetrate the fraud.

From our research, it is clear that while pressure came from the CEO and COO, the CFO was the primary manipulator of the financial statements. Unfortunately, we could not (neither could the courts) determine how much knowledge the CEO and COO had about the different types of fraudulent financial transactions that were taking place. However, in order to keep stock options valuable (the CEO, COO, and CFO all had stock options worth tens of millions of dollars) they were motivated to maintain high stock prices by meeting Wall Street earnings expectations every quarter.

Because so many people were involved in preparing the financial statements of this large corporation, the need to involve others in the fraud became necessary. The CFO recruited the controller, the vice-president of accounting, the vice president of financial reporting, and the director of financial reporting into the fraud. This 'inner circle' of perpetrators understood most elements of the fraud, and recruited others to manipulate individual fraudulent transactions (including various controllers at the company's subsidiaries). Subsidiary controllers then recruited others within their own organizations to help perpetrate the fraud. 
Though the number of people involved in the fraud expanded over the years, the detailed knowledge of the overall fraudulent behavior was generally limited to the persons in higher level positions.

Yet, even the principal perpetrators hadn't known how many people were actually involved or the full extent of the financial statement losses. Court documents suggest that those in the third and fourth generations had very little knowledge of the scope of the fraud, yet, still manipulated certain transactions that enabled the fraud to be executed.

Court documents suggest that those who participated in the fraud did so for various reasons. Several individuals, especially those at the executive level, became involved because they were promoted and received higher salaries. Nearly all the participants received, as a result of a higher stock price, more valuable stock options. Other individuals participated because of fear of dismissal or reprisal. Third and fourth generation participants, usually with little knowledge of the overall scheme, participated because their superiors told them to do something, or because they felt they did not understand exactly what was going on. Within the inner circle, individuals participated because they trusted their colleagues and because, at first, the fraudulent amounts were small. As a whole, the group rationalized their actions as acceptable by making 'seemingly small rationalizations'.

The total amount of the financial statement manipulation was between $\$ 1$ billion and $\$ 3$ billion. Before the fraud was discovered, more than 30 people participated in the fraud. Many of these individuals had different levels of knowledge regarding the fraud. While some of the perpetrators had complete knowledge of the unethical acts that were occurring, others performed tasks simply because they were "asked to". Those who had full knowledge of the fraud rationalized their acts as acceptable. They believed that the unethical financial statement manipulations would only be necessary for a limited time. However, when regulators discovered the fraudulent financial statements, the fraud had been occurring for over four years.

\section{Power and the Decision to Commit Financial Statement Fraud}

As illustrated in the case, fraud schemes are replete with the use and abuse of power. Perceptions of personal power and social power influence the initial decision to initiate the financial statement fraud and also the recruitment of others to assist and abet in the scheme. Personal power has been described as the ability that a person has to carry out his or her own will despite resistance (Weber, 1947). Social power is the ability to control the resources and outcomes of others (Overbeck and Park, 2001).

Extensive research has shown that power is often misused by individuals and may lead to an array of negative consequences. For example, power often impairs cognition and judgments. Powerful people are more likely to have flawed assessments of others' interests and emotions (Keltner and Robinson, 1997), to use stereotypes in forming opinions of others (Fiske, 1993), to seek out information that confirms their own preferences and beliefs (Ebenbach and Keltner, 1998), and to objectify others and treat them as a means to an end (Gruenfeld et al., 2008). Power can have a significant effect on the way individuals think about problems and the consideration of potential solutions to overcome the obstacles.

In evaluating the role of power in financial statement fraud, we will first consider the decision to initiate a financial statement fraud and the decision-maker's power in this process. When viewed through the lens of the fraud triangle, we argue that power differentially affects the perceptions of pressure, opportunity, and rationalization. Personal power is likely to be inversely related to pressure. An individual that is high in power feels in control of his or her outcomes and is less susceptible to external pressure (Pfeffer and Fong, 2005). Power tends to 
reduce the threat of losses (Inesi, 2010) which alters the motivational mechanisms within individuals. For example, a powerful CEO that is also Chairman and feels in control of the board of directors will likely feel less threat of negative consequences from unmet expectations than one with less power. Similarly, the CEO/Owner of a private company is in a position of power relative to an executive of a public company regarding the personal outcomes associated with the company's performance. Thus, the owner of the private company would typically feel significantly less pressure to fudge the numbers.

Proposition 1: The more personal power that an individual has, the less likely he or she is to perceive external pressure to perpetrate a financial statement fraud.

On the other hand, power is likely to increase the perception of opportunity. Power tends to reduce the influence of constraints on the pursuit of goals (Keltner, et al., 2003). When constraints are discounted, the opportunities look more plausible. Having power tends to deactivate the behavioral inhibition system that generally sends the warning signals about potentially detrimental behaviors (Anderson and Berdahl, 2002). Thus, power increases the likelihood of risk-seeking behavior

(Anderson and Galinsky, 2006) and the disregard for social norms (Galinsky et al., 2008).

Such power related biases are liable to influence the viability of an opportunity to accomplish a goal by any means necessary, even financial statement fraud. For instance, a CFO with substantial power is more likely to believe that he or she could manage a fraud scheme without getting caught than a CFO with less power.

Proposition 2: The more personal power that an individual has, the more likely he or she is to perceive an opportunity to perpetrate a financial statement fraud.

Rationalization is the third element of the fraud triangle that contributes to unethical decisionmaking. Research suggests that individuals with high power are often susceptible to moral hypocrisy and are less strict than the powerless in the moral judgment of their own behavior (Lammers et al., 2010). They often feel a sense of entitlement even if their behavior may cause harm to others (Rosenblatt, 2012). The powerful are more prone than those with less power to the rationalization of self interest (Keltner, et al., 2006). The rationalization may be so compelling that the individual makes seemingly irrational judgments of the morality of his or her behavior. It was recently reported that Dennis Kozlowski, the disgraced former CEO of Tyco International, rejected a plea deal that would have reduced his prison sentence because he was living in a "CEO-type bubble" and had "rationalized" that he was not guilty (Dolmetsch and Van Voris, 2012).

Proposition 3: The more personal power that an individual has, the more likely he or she will develop rationalizations for perpetrating a financial statement fraud.

\section{Power and the Recruitment of Co-conspirators}

Social power has been repeatedly studied by management and social psychology scholars and a number of theories and taxonomies of power have emerged. The most prominent of these approaches include the power-dependence theory (Emerson, 1962), Kipnis, Schmidt, and Wilkinson's typology of influence tactics (Kipnis et al., 1980), and the French and Raven framework of power (French and Raven, 1959). Recent research argues that these theories of power have become the most commonly referenced frameworks for understanding social power in management (Kim et al., 2005). In applying these different taxonomies to the case 
study, we determined that the French and Raven (1959) framework provides the most insight into the recruitment process as it is the only framework that suggests how power is derived between two individuals. Such a perspective is important when analyzing the relationship that takes place in the recruitment of individuals in a financial statement fraud (Dapiran and Hogarth-Scott, 2003).

French and Raven's theory suggests that there are five different sources of social power. The power possessed by person A is based on person B's perception of A's role, characteristics, and relationship with B. Specifically, the types of power possessed by A may include (1) coercive power (B perceives that A has the ability to punish B if B does not comply with A's demands), (2) reward power (B perceives that A has the ability to reward B if B does comply with A's wishes), (3) expert power (B perceives that A possesses special knowledge or expertise that merits deference), (4) legitimate power (B perceives that A has a legitimate role or position that obligates B to follow A's direction), and (5) referent power (B identifies with, admires, or respects A so B wishes to emulate A). It is important to note that in the case of power, perception becomes reality (Wolfe and McGinn, 2005). In other words, even if A would not be deemed to have any rightful power over B by impartial observers, if B perceives A to have power, then A does have power.

Drawing upon these five types of power, we propose a power-based model to help explain how individuals use power to recruit others to participate in financial statement fraud. In developing the model, we propose that a person in a position of power (Person A), such as a $\mathrm{CEO}$ will use power to influence another individual (Person B) to participate in the fraudulent scheme. In so doing, A seeks to apply pressure on B, help B perceive a reasonable opportunity, and provide possible rationalizations for B. This process is shown in Figure I:

\section{Insert Figure I About Here}

\section{Pressure}

Pressure is a key component of recruiting co-conspirators to participate in a fraud. People in positions of power often have the ability to apply pressure on targets of interest. Perceived reward power is the ability of the conspirator to convince potential co-conspirators that he or she will provide desired benefits through participation in a financial statement fraud. The recruiter may encourage the individual to participate in the scheme through the promise of a large bonus, rewards from valuable stock options, other types of equity payments, or possibly even a job promotion.

Perceived coercive power is the ability of the conspirator to make the potential co-conspirator perceive potential punishment if he or she doesn't participate in a financial statement fraud. This potential punishment is usually based on fear (Politis, 2005). If the potential coconspirator perceives that the perpetrator has the ability to punish him or her in any way, the perpetrator begins to exercise a form of coercive power over that individual. From a coercive power perspective, the recruiter may pressure a potential co-conspirator to participate in the scheme by suggesting they may lose their job, receive public humiliation, be victimized as a whistle-blower, or be punished in some other way. While not as common, expert power may be used to pressure individuals to participate in the scheme by suggesting that the recruiter has expert knowledge about the business and how it should run. Similarly, since financial statement fraud typically occurs from the top-down, conspirators may pressure employees to participate because he or she 'is the boss'. Finally, referent power may be used to pressure trusted friends and colleagues to participate in the scheme.

Proposition 4: Reward power and coercive power are the most effective forms of social power that may be used to apply pressure on potential co-conspirators. 


\section{Opportunity}

A person that is being recruited to participate in fraud may feel ample pressure to take part and thus have the desire or motivation to do so. However, another important element in the process is the perception that there is a reasonable opportunity to commit the fraud. Much of the perception of opportunity is related to the person's own job responsibilities and skills. For example, an accountant that has primary responsibility for managing division accounts may feel some sense of opportunity to alter the numbers by virtue of his or her position. Yet, senior management may further influence the perception of opportunity through the use of social power.

It is likely that the original conspirator will influence his or her target of influence so that they believe their actions can be made without threat of serious consequence. Based on our case analysis, we propose that the most common type of power used to create perceived opportunities include expert and legitimate power.

Perceived expert power is the ability of the conspirator to use influence through means of expertise or knowledge. From an expert power perspective, perpetrators influence victims to believe that they have insight and knowledge about the financial transactions of the firm, including how the transactions are to be observed and recorded. An example of a financial fraud that appears to have been the result of perceived expert power is Enron. Certain members of management claimed to have expert knowledge regarding complicated business organizations and arrangements.1

Individuals, who would have otherwise refused to join the conspiracy based upon personal ethical standards, convinced themselves that the conspirators knew more about the complex transactions than they did.

Perceived legitimate power is the ability of Person A to convince Person B that A truly does have real power over him or her. In business settings, individuals such as the chief executive officer, or other members of management, claim to have legitimate power to make decisions and direct the organization - even if that direction is unethical. In this way, conspirators assume authoritative roles and convince potential co-conspirators that their authority is legitimate. Such perceptions may help the recruit feel that the opportunity is indeed reasonable since the leader supports and/or condones the action.

Proposition 5: Expert power and legitimate power are the most effective forms of social power that may be used to increase the perception of opportunity for potential coconspirators.

\section{Rationalization}

We propose that fraud perpetrators use power to encourage victims to rationalize their actions as acceptable. While perpetrators will use all five types of power to do this, we suggest perpetrators most often use referent, legitimate, and expert power for rationalization. Perceived referent power is the ability of the conspirator to relate to the target of influence (co-conspirators). Conspirators using referent power will build relationships of confidence with potential co-conspirators.

Perpetrators often use perceived referent power to gain confidence and participation from potential co-conspirators when performing unethical acts. Many individuals, when persuaded by a trusted friend to participate in a financial statement fraud, will rationalize the actions as being justifiable. Perpetrators may influence their friends and co-workers to participate in the fraud by portraying attitudes such as, 'everyone is doing it', 'it's no big deal', 'it's only 
temporary' or 'it's necessary'. Furthermore, perpetrators will influence colleagues and friends simply by modeling inappropriate behavior. When perpetrators openly engage in dishonest acts, it suggests that inappropriate behavior is acceptable and within the norms of the organization.

From a legitimate power perspective, perpetrators will encourage subordinates to rationalize the fraud as acceptable. Perpetrators may do so by labeling the fraud as acceptable and by suggesting that, 'this is how things are done around here'. When individuals within the organization see their bosses engaging in fraudulent behavior, it sends a message that such behavior is acceptable. 'If it wasn't acceptable', these people rationalize, 'the boss wouldn't be doing it'.

Finally, from an expert-power perspective, many potential victims simply accept that they must engage in such unethical behavior because 'others know more than I do about the operations of the business, market, industry, etc.' Such an attitude may be even more compelling in fraudulent financial scandals when lower-level personnel see both internal and external auditors signing off (or accepting) the fraudulent transactions.

\section{Proposition 6: Referent power, legitimate power and expert power are the most effective forms of social power that may be used to help potential coconspirators form satisfactory rationalizations regarding fraudulent behavior.}

\section{Summary of the Model}

In our model, we propose that whether or not the individual (person B) is recruited into the financial statement fraud depends upon various factors such as the individual's desire (Person B) for a reward or benefit, the individual's fear of punishment, the individual's perceived level of personal knowledge, the individual's level of obedience to authority, and the individual's personal relationship needs. The model displayed is interactive meaning that these five types of power often work together to influence a potential perpetrator. For example, if reward power were being used to influence another person, and the individual in position $\mathrm{B}$ had a specific need for a reward or benefit, then the perceived reward or benefit that A must provide doesn't have to be as significant as if B were not in need of such a reward or benefit. In this sense, when successful recruitment occurs, there is a balance between B's susceptibility of power and A's exertion of power.

Once the potential co-conspirator (position B) becomes involved in the unethical scheme, this person often switches to position A, and becomes another perpetrator of the fraud scheme. Using his or her own perceived power with his or her subordinates, this person will often recruit others to participate in the unethical acts. This spillover effect continues until an individual either blows the whistle or until the scheme(s) becomes so large and egregious that it is discovered. As the fraud scheme continues to grow, we propose that there is a direct effect on the organizational culture of the firm. Culture has been explained as, "the collective programming of the mind that manifests itself not only in values, but also in superficial ways, including symbols, heroes, and rituals" (Hofstede, 2001, p. 1). It has been suggested that spoiled organizational images often transfer to additional organizational members (Sutton and Callahan, 1987). Therefore, the once ethical organization, with no members involved in the financial statement fraud scheme, gradually transforms itself into an organization that fosters unethical behavior. In the process, individuals, as a result of socialization (Anand, et al., 2004) and diffusion (Myers, 2000; Baker and Faulkner; 2003), begin to understand and accept the scheme as justifiable. 


\section{Evaluation of the Model with the Case}

Using our proposed model, we can better understand the process of recruitment as illustrated in the case study. The model suggests that unethical acts begin with an individual conspirator or, in some cases, a small group of conspirators. These individuals are usually motivated because they rationalize that the consequences (lack of rewards or penalties) of not committing the act are worse than the consequences of the act itself. To this end, individuals begin to perpetrate unethical acts, and, on an 'as-needed basis', recruit others to participate in the scheme.

With nearly 30 individuals involved in perpetrating the fraud, our investigation suggests that all five types of power were used. For example, in court documents, perpetrators often discussed stock options (reward power), the promise of promotions (reward power), the fear of a lower stock price (coercive power), the fear of being unsuccessful (coercive power), whistle-blower fears (coercive power), trust between co-workers (referent power), obedience to management (legitimate power), as well as the lack of knowledge that many of them had (expert power).

\section{Discussion and Opportunities for Future Research}

While our model on the recruitment of individuals into financial statement fraud schemes is grounded in power theory, it is difficult to empirically test the model (this is true with most fraud models). First, many acts, because of public embarrassment and legal fears, are handled quietly and never made public. Second, even when the fraud is made public, most of the details about colluding perpetrator relationships never surface. Despite these challenges, we are hopeful that our model can be tested empirically.

Auerbah and Dolan (1997) suggest that understanding the various types of power does not tell us how power is used to influence others. Rather, they explain that it is important to understand the strategies that are employed by individuals - in the case of this research - the strategies used to influence others to participate in financial statement fraud. Future research must help identify the exact strategies that perpetrators use to recruit others to participate in financial statement fraud schemes.

With financial statement frauds being perpetrated throughout all parts of the world, there is a need to address the international aspects of power. We must better understand how a country's culture affects the strategies that are employed by individuals to influence others. This research must address issues such as whether one type of power is more dominate than the other types of power regardless of culture. There are now several excellent frameworks for studying cultural values including Hofstede (1980), Schwartz (1992, 2005), Trompenaars (1993) as well as the framework provided by House, et al. (2004). Similarly, it is important to understand if one type of power always plays a dominant role in organizational corruption or

if power is situational. Along this same line of reasoning, research must address if individuals are inherently susceptible to certain types of power. Future research must examine how differences in personalities and backgrounds affect responses to power, especially the way that different personalities respond when coupled with the influence to participate in financial statement fraud and other forms of organizational corruption. Some basic descriptive studies might address the range of criteria that individuals use to define the relationships they have with those who are in positions of power. This area must address how the various types of power are defined.

Furthermore, various constructs such as the desire for a reward or benefit, the fear of punishment, the lack of knowledge, the level of obedience, and relationship needs must be more fully understood. Understanding the emotions surrounding these constructs may help us 
understand why some people become involved in organizational corruption while others do not.

\section{Conclusion}

In this paper, we have proposed a power-based, dyad reciprocal model to explain the process by which fraud perpetrators recruit individuals to participate in financial statement frauds. Previous research has suggested that a key element of fraud prevention is educating employees and others about the serious of fraud and informing them what to do if fraud is suspected (Albrecht et al., 2011). Educating employees about fraud and providing fraud awareness training helps ensure that frauds that do occur are detected at early stages, thus limiting financial exposure to the corporation and minimizing the negative impact of fraud on the work environment. The model provided in this paper provides shareholders with a valuable tool to educate employees and others about fraud.

The model presented fills an important void in the fraud literature. For many years, the fraud triangle, with its limited predictive ability, has provided the accounting and criminology fields with a basis as to why individuals participate in fraudulent behavior. The fraud triangle has been used to further education, research, and practical agendas. As such, it has provided a framework to reference when establishing safeguards and other controls to protect businesses from fraud.

Furthermore, the fraud triangle has allowed the scientific community to better understand the constructs that are at play when an individual becomes involved in financial statement fraud. Our model provides a valuable corollary to the fraud triangle. Used together, we can not only understand how a single individual becomes involved in fraud but how entire management teams become involved in fraud. If the model described in this paper is used by organizations in their fraud prevention programs, employees can better identify and understand the types of power that may possibly influence them to participate in fraud schemes. The practical application of the model is that it empowers individuals within an organization against negative and/or unethical influence. 


\section{Figure I: Dyad Reciprocal Model}

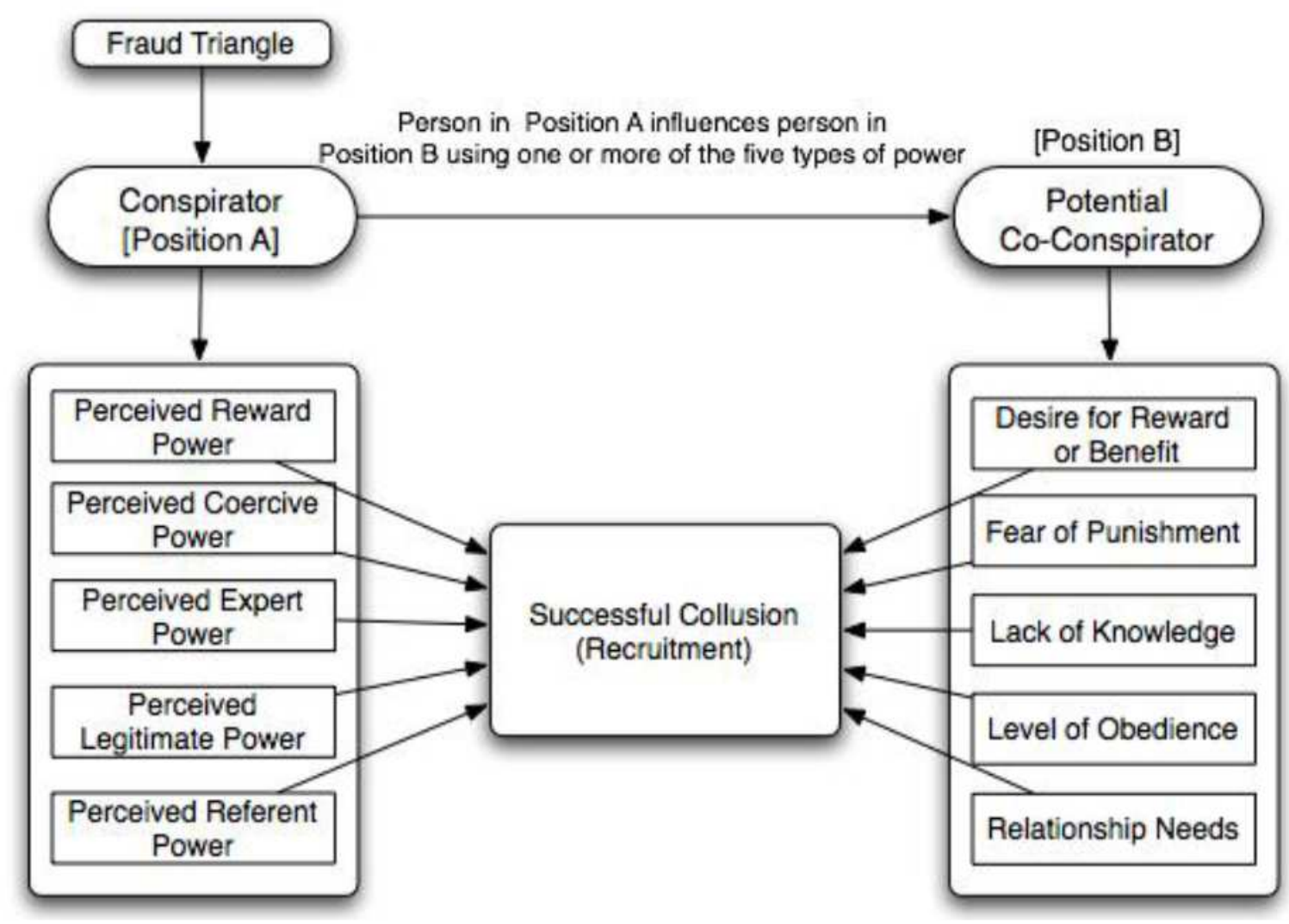




\section{References:}

Albrecht, W. S., M. Romney, D. Cherrington, R. Paine and A. Roe: 1981, How to Detect and Prevent Business Fraud (Prentice-Hall: Englewood Cliffs, NJ).

Albrecht, W. S., C. C. Albrecht and C. Albrecht: 2004, 'Fraud and Corporate Executives: Agency, Stewardship and Broken Trust', Journal of Forensic Accounting 5, 109-130.

Albrecht, W. S., C. O. Albrecht and C. C. Albrecht: 2011, Fraud Examination, $4^{\text {th }}$ Edition (Cengage Learning: Mason, Ohio).

Anand, V., B. E. Ashforth and J. Mahendra: 2004, 'Business as Usual: The Acceptance and Perpetuation of Corruption in Organizations', Academy of Management Executive 18, 39-53. Anderson, C. and J. L. Berdahl: 2002, 'The Experience of Power: Examining the Effects of Power on Approach and Inhibition Tendencies', Journal of Personality \& Social Psychology 83, 1362-1377.

Anderson, C. and A. D. Galinsky: 2006, 'Power, Optimism, and Risk-Taking', European Journal of Social Psychology 36, 511 - 536.

Apostolon, N. and D. L. Crumbley: 2005, 'Fraud Surveys: Lessons for Forensic Accounting', Journal of Forensic Accounting 4, 103-118.

Aronson, E.: 1992, 'The Return of the Repressed: Dissonance Theory Makes a Comeback', Psychological Inquiry 3, $303-311$.

Association of Certified Fraud Examiners: 2012, ACFE Report to the Nation on Occupational Fraud \& Abuse (Association of Certified Fraud Examiners: Austin, TX)

Auerbach A. and S. Dolan: 1997, Organizational Behavior: A Canadian Primer (ThomsonITP Nelson: Scarborough, ON).

Bandura, A.: 1999, 'Moral Disengagement in the Perpetration of Inhumanities', Personality and Social Psychology Review 3, 193-209.

Baker, W. E., R. R. Faulkner: 2003, 'Diffusion of Fraud: Intermediate Economic Crime and Investor Dynamics', Criminology 41, 1173 - 1206.

Brief, A. P., R. T. Buttram and J. M. Dukerich: 2000, 'Collective Corruption in the Corporate World: Toward a Process Model', in M. E. Turner (Ed.) Groups at Work: Advances in Theory and Research (Lawrence Erlbaum \& Associates: Hillside, NJ).

Brass, D. J., K. D. Butterfield, B. C. Skaggs: 1998, 'Relationships and Unethical Behavior: A Social Network Perspective', Academy of Management Review 23, 14 -31.

Burke, R. J.: 2010, 'Crime and Corruption in Organizations', in R. J. Burke, E. C. Tomlinson and C. L. Cooper (Ed.), Crime and Corruption in Organizations: Why It Occurs and What to Do About It (Gower Publishing: Surrey, UK), 1 - 64.

Carson, T. L.: 2003, 'Self-Interest and Business Ethics: Some Lessons of the Recent Corporate Scandals', Journal of Business Ethics 43, 389-394.

Castellano, J. G. and B. C. Melancon: 2002, 'Letter to Members - February 2, 2002', American Institute of Certified Public Accountants Archive. Available at http://cpcaf.aicpa.org.

Cressey, D.: 1953. Other People's Money: A Study in the Social Psychology of Embezzlement (Free Press: Glencoe, Ill).

Dapiran, P. G. and S. Hogarth-Scott: 2003, 'Are Co-Operation and Trust Being Confused with Power? An Analysis of Food Retailing in Australia and the UK', International Journal of Retail \& Distribution Management 31, 256-267.

Davis, J. H., F. D. Shoorman and L. Donaldson: 1997, 'Toward a Stewardship Theory of Management', Academy of Management Review 22, 20 - 47.

Dolmetsch, C. and B. Van Voris: 2012, 'Ex-Tyco Chief Kozlowski Says He Rejected Plea Agreement', Bloomberg.com. 
Donaldson, L. and J. H. Davis: 1991, 'Stewardship Theory or Agency Theory: CEO

Governance and Shareholder Returns', Australian Journal of Management 16, 49 - 65.

Dozier, J. B. and M. P. Miceli: 1985, 'Potential Predictors of Whistle-Blowing: A Pro-Social

Behavior Perspective', Academy of Management Review 10, 823-836.

Earle, J. S., A. Spicer and K. S. Peter: 2010, 'The Normalization of Deviant Organizational

Practices: Wage Arrears in Russia', Academy of Management Journal 53, 218 - 237.

Ebenbach, D. H. and D. Keltner: 1998, 'Power, Emotion, and Judgmental Accuracy in Social

Conflict: Motivating the Cognitive Miser', Basic and Applied Social Psychology 20, 7 - 21.

Elias, R. Z.: 2002, 'Determinant of Earnings Management Ethics Among Accountants',

Journal of Business Ethics 40, 33 - 45.

Emerson, R. M.: 1962, 'Power-Dependence Relations', American Sociological Review 27, 31 -40 .

Epstein, B. J., R. Nach and S. M. Bragg: 2010, GAAP 2011: Interpretation and Application of Generally Accepted Accounting Principles (John Wiley \& Sons: Hoboken, New Jersey). Farber, D. B.: 2005. 'Restoring Trust after Fraud: Does Corporate Governance Matter?', The Accounting Review 80, 539-561.

Ferrell, O. C. and L. Ferrell: 2011, 'The Responsibility and Accountability of CEOs: The Law Interview with Ken Lay', Journal of Business Ethics, 100, 209 - 219.

Festinger, L.: 1957, A Theory of Cognitive Dissonance (Row \& Peterson: Evanston, Illinois). Fiske, S. T., 1993, 'Controlling Other People', American Psychologist 48, 621 - 628.

French, J. R. P., Jr. and B. Raven: 1959, The Bases of Social Power. In D. Cartwright (Ed.), Studies in Social Power (University of Michigan Press: Ann Arbor, MI).

Galinsky, A. D., J. C. Magee, D.H. Gruenfeld, J.A. Whitson and K.A. Liljenquist: 2008, 'Power Reduces the Press of the Situation: Implications for Creativity, Conformity, and Dissonance', Journal of Personality and Social Psychology 95, 1450 - 1466.

Gruenfeld, D. H., M. E. Inesi, J. C. Magee and A.D. Galinsky: 2008, 'Power and the Objectification of Social Targets', Journal of Personality and Social Psychology 95, 111-127. Hofstede, G.: 1980, Culture's Consequences: International Differences in Work- Related Values (Sage Publications: Thousand Oaks, California).

Hofstede, G.: 2001, Cultural Consequences: Comparing Values, Behaviors, Institutions, and Organizations across Nations (Sage Publications: Thousand Oaks, California).

Hogan, C. E., R. Zabihollah, R. A. Riley and U. K. Velury: 2008, 'Financial Statement Fraud: Insights from the Academic Literature', Auditing: A Journal of Practice \& Theory 27, 231 252.

House, R.J., P. J. Hanges, M. Javidan, P. W. Dorfman and V. Gupta: 2004, Culture, Leadership, and Organizations: The GLOBE Study of 62 societies (Sage Publications: Thousand Oaks, California).

Inesi, M. E.: 2010, 'Power and Loss Aversion', Organizational Behavior \& Human Decision Processes 112, 58-69.

Jensen, M.C. and W. H. Meckling: 1976, 'Theory of the Firm: Managerial Behavior, Agency Costs, and Ownership Structure', Journal of Financial Economics 3, 305 - 360.

Keltner, D. and R. J. Robinson: 1997, 'Defending the Status Quo: Power and Bias in Social Conflict', Personality and Social Psychology Bulletin 23, 1066-1077.

Keltner, D., D. H. Gruenfeld and C. Anderson, 2003, 'Power, Approach, and Inhibition', Psychological Review 110, 265-284.

Keltner, D., C. A. Langner, M. L. Allison: 2006, Power and Moral Leadership. Moral Leadership: The Theory and Practice of Power, Judgment and Policy, (Jossey-Bass: San Francisco, California).

Kim, P. H., R. L. Pinkley and A. R. Fragale: 2005, 'Power Dynamics in Negotiations, The Academy of Management Review 30, 799-822. 
Kipnis, D., S. M. Schmidt and I. Wilkinson: 1980, 'Intraorganizational Influence Tactics: Explorations in Getting One's Way', Journal of Applied Psychology 65, 440 - 452.

Kohlberg, L.: 1984, The Psychology of Moral Development, (Harper and Row: San Francisco, California).

Lammers, J., D. A. Stapel and A. D. Galinsky: 2010, 'Power Increases Hypocrisy:

Moralizing in Reasoning, Immorality in Behavior', Psychological Science 21, 737- 744.

LaSalle, R. E.: 2007, 'Effects of the Fraud Triangle on Students' Risk Assessments', Journal of Accounting Education 25, 74 - 87.

Myers, D. J.: 2000, 'The Diffusion of Collective Violence: Infectiousness, Susceptibility, and Mass Media Networks', American Journal of Sociology 106, 173 -208.

National Commission on Fraudulent Financial Reporting: 1987, Report of the National

Commission on Fraudulent Financial Reporting (Government Printing Office: Washington,

D. C.).

Near, J. P. and M. P. Miceli: 1986, 'Retaliation Against Whistle-Blowers: Predictors and

Effects', Journal of Applied Psychology 71, 137-145.

Nocera, J.: 2008, Good Guys \& Bad Guys (Portfolio: New York, NY).

Overbeck, J. R. and B. Park: 2001, 'When Power Does Not Corrupt: Superior Individuation

Processes Among Powerful Perceivers', Journal of Personality \& Social Psychology 81, 549565.

Pfeffer, J. and C. T. Fong: 2005, 'Building Organization Theory from First Principles: The

Self-Enhancement Motive and Understanding Power and Influence', Organization Science 16, 372-388.

Pinder, C. C.: 1998, Motivation in Work Organizations, (Prentice Hall: Upper Saddle River,

New Jersey).

Politis, J. D.: 2005, 'The Influence of Managerial Power and Credibility on Knowledge

Acquisition Attributes', Leadership \& Organization Development Journal 26, 197-214.

Power, M. K.: 2003, 'Auditing and the Production of Legitimacy', Accounting,

Organizations, and Society 28, 379-394.

Pujas, V.: 2003, 'The European Anti-Fraud Office (OLAF): A European Policy to Fight

Against Economic and Financial Fraud?', Journal of European Public Policy 10, 778-797.

Ramos, M.: 2003, 'Auditors' Responsibility for Fraud Detection', Journal of Accountancy

195, $28-35$.

Robison, H. D. and R. Santore: 2011, Managerial Incentives, Fraud, and Monitoring, The

Financial Review 46, 281 - 311.

Rockness, H. and J. Rockness: 2005, 'Legislated Ethics: From Enron to Sarbanes- Oxley, the Impact on Corporate America', Journal of Business Ethics 57, 31 - 54.

Rosenblatt, V.: 2012, 'Hierarchies, Power Inequalities, and Organizational Corruption', Journal of Business Ethics 111, 237-251.

Schwartz, S. H.: 1992, 'Universals in the Content and Structure of Values: Theoretical Advances and Empirical Test in 20 Countries', Advances in Experimental Social Psychology 25, 1-65.

Schwartz, S. H.: 2005, Basic Human Values: Their Content and Structure Across Countries, In A. Tammayo and J. B. Porto (Eds.), Values and Behavior in Organizations (Vozes:

Petropolis, Brazil).

Strang, D., and S. A. Soule: 1998, 'Diffusion in Organizations and Social Movements: From Hybrid Corn to Poison Pills', Annual Review of Sociology, 24, 265 - 290.

Sutherland, E.: 1949, White Collar Crime (Dryden Press: New York, NY).

Sutton, R. and A. L. Callahan: 1987, 'The Stigma of Bankruptcy: Spoiled Organizational Image and its Management', Academy of Management Journal 30, 405 - 436. 
Tenbrunsel, A. E. and D. M. Messick: 2004, 'Ethical Fading: The Role of Self- Deception in Unethical Behavior', Social Justice Research 17, 223-236.

The Committee of Sponsoring Organizations of the Treadway Commission: 2002, Fraudulent Financial Reporting: 1987-1997 An Analysis of U.S. Public Companies (Government Printing Office: Washington, D. C.).

Tsang, J.: 2002, 'Moral Rationalization and the Integration of Situational Factors and Psychological processes in Immoral Behavior', Review of General Psychology 6, 25- 50. Trompenaars, F.: 1993, Riding the Waves of Culture: Understanding Diversity in Global Business (Irwin Professional Publishing: Chicago, IL).

Uddin, N. and P. R. Gillet: 2002, 'The Effects of Moral Reasoning and Self- Monitoring on CFO Intentions to Report Fraudulently on Financial Statements', Journal of Business Ethics 40, 15 - 32.

Weaver, G. R.: 2006, 'Virtue in Organizations: Moral Identity as a Foundation for Moral Agency', Organization Studies 27, 341-368.

Weber, M.: 1947, The Theory of Social and Economic Organization (Free Press: New York, NY).

Wolfe, D. T. and D. R. Hermanson: 2004, 'The Fraud Diamond: Considering the Four Elements of Fraud', The CPA Journal, December.

Wolfe, R. J. and K. L. McGinn: 2005, 'Perceived Relative Power and its Influence on Negotiations', Group Decision and Negotiation 14, 3-20.

Zyglidopouslos, S. C. and P. J. Flemming: 2008, 'Ethical Distance in Corrupt Firms: How Do Innocent Bystander's Become Guilty Perpetrators?', Journal of Business

Ethics 78, 265 - 274.

Zyglidopoulos, S. C. and P. J. Flemming: 2009, The Escalation of Corruption, in R. J. Burke and C. L. Cooper (Eds), Research Companion to Corruption in Organizations (Edward Elgar: Cheltenham, UK), $104-119$. 